\title{
COMENTARIO A "POR UN GIRO ANALÍTICO EN SOCIOLOGIA"
}

\author{
SALVADOR GINER \\ Universidad de Barcelona, España \\ sginer@diginter.com
}

Agradezco a Fernando Aguiar, Andrés de Francisco y José Antonio Noguera que hayan solicitado mi opinión sobre sus consideraciones acerca de la sociología analítica, en las que defienden lo que llaman "giro analítico" en esa disciplina. Hela aquí.

El documento alude a la sociología analítica como movimiento intelectual relativamente nuevo, que despierta hoy mucha atención, y cuyos aportes científicos a la ciencia social son y van a seguir siendo, considerables. Mis breves comentarios girarán en torno a la cuestión de saber hasta qué punto la llamada sociología analítica es distinta de la tradición sociológica principal, que es, a mi juicio, la que con mayor eficacia ha permitido y fomentado el avance de esta ciencia social a través del tiempo.

Si la sociología analítica no difiere, o difiere poco, de dicha tradición, habrá que replantearse la aspiración a crear una escuela más entre las otras de las que disponemos. En tal caso, nuestros esfuerzos deberían orientarse a reivindicar la solidez de la línea principal de investigación, y a reforzarla. No por ello, sin embargo, debería disolverse cualquier movimiento hacia la consolidación de una escuela como la que la sociología analítica representa pues, por lo menos, no es hostil a la corriente principal, sino que comparte mucho terreno con ella. ( $\mathrm{Y}$ que, para colmo, se siente heredera de ella.) En cualquier caso, la analítica, aseveran, sería la mejor fundamentada de las múltiples existentes.

Dadas mis coincidencias con la posición por la que aboga el documento -y la extrema limitación de espacio del que dispongo- me permitiré la osadía de referir al lector a diversas publicaciones mías en las que concurro con ellos. Me ahorraré así repeticiones y podré atenerme al angosto espacio que se me concede.

El "diagnóstico crítico de la sociología actual" con el que comienza el documento se me antoja impecable. Tengo publicados en las páginas de la RIS similares ataques contra el relativismo epistémico y el "todo vale" al que los autores se refieren. (Véase "Descrédito de la verdad", RIS, $\left.n^{\circ} 31,2002.\right)$

El elenco de características de aquello que aúna a los sociólogos analíticos, expresado en documento, merece algunos comentarios específicos.

a) Aunque el documento invoca un wittgensteiniano "aire de familia" como territorio metodológico común para los analíticos, su presentación debe mucho más a algunos estudiosos (Barbera, Hedström, Swedberg. et alii) que a una corriente algo más abierta, que es la que tal vez algunos favoreceríamos. La línea señalada por estos sociólogos 
cuerdamente indica que la metodología es epistemología, pero al describir la primera tiende a establecer una reglas muy formalizadas del juego que estrechan las lindes de la tarea sociológica. Ello coadyuva a que la sociología analítica se consolide como escuela -para sus iniciados- pero debilita sus ligámenes con lo que denomino tradición sociológica principal. Sus ligámenes, esto es, con las aportaciones de Marx, Tocqueville, Tönnies, Simmel, Pareto y Durkheim, más otros avances posteriores -de Mannheim a Merton- sobre cuyas sólidas pesquisas se asienta la corriente principal. Los autores del documento reconocen la bondad de ese camino puesto que hasta invitan a "volver a Weber" en su conclusión. Tal vez convenga recordarles que es un viaje para el que, para quienes jamás abandonaron a Weber (ni a Simmel, ni a Pareto, ni a Elias, por evocar algunos nombres), no eran menester alforjas.

b) La tradición o corriente principal, evidentemente, reúne las características de rigor conceptual, racionalidad, especificación de secuencias causales, evitación del lenguaje nebuloso, y demás defectos propios de la sociología más huera, por un lado, o de la descripción empírica y sociográfica productora de materiales poco o nada interesantes, yerma de hipótesis importantes, y sólo capaz de algunas correlaciones o análisis factoriales más o menos significativos, por otro.

c) Desde este punto de vista, tengo serias dudas de que la tradición sociológica que desde Marx y Tocqueville, hasta Merton y Boudon ha generado un flujo valiosísimo de aportaciones a la ciencia social, y que, más allá de toda duda, ha enriquecido nuestro patrimonio cognoscitivo científico, pueda acomodarse al lecho de Procusto de algunas (y sólo algunas) de las exigencias metodológicas de la sociología analítica, tal y como parece presentarla el documento que comento. Debe entenderse que mis reservas no van en contra de la formalización, sino contra que ésta (y en muchos casos, la matematización) sea la panacea contra el oscurantismo y la insustancialidad que, convincentemente, denuncian los autores. Hay diversos modos de hacer sociología, lo cual no significa que debamos reconocer el "todo vale". Algunos modos son mejores que otros. Algunos valen más que otros. (Véase mi trabajo "Para hacer sociología", incialmente publicado en la revista filosófica Teorema, Vol. VI 3-4, 1976. Sus postulados están reproducidos en el Diccionario de filosofía, de José María Ferrater Mora, entre otros lugares accesibles.)

d) Incidentalmente, parte significativa de la "sociología ensayística" posee aportaciones ocasionales de gran calado: identificarlas es importante, pero no es factible adentrarse ahora en este asunto. No siempre tal sociología -hasta cuando no es explícitamente "analítica"- admite el "todo vale" ni niega la cumulatividad ni el progreso de la sociología como ciencia social. La sociología analítica tiene que ser bastante excluyente, según la lógica mínima de toda escuela que se precie, pero no universalmente excluyente. Debe eliminar todo fundamentalismo, aunque asuma que hay unas vías -las suyas- que son más fructíferas que otras para resolver cierta suerte de enigmas.

e) No puede ser mayor mi acuerdo con las posiciones expresadas en el documento, habida cuenta de que su reivindicación de las intenciones humanas como parte de la panoplia interpretativa de la sociología analítica encontró ya expresión en mi trabajo "Intenciones humanas y estructuras sociales: una introducción a la lógica situacional". 
(Inicialmente publicado en Cuadernos Económicos, 1977, 3/4, pero también en M. Cruz, comp. Acción Humana, Ariel, 1977, precisamente en un esfuerzo por codificar de algún modo lo debería entenderse por "corriente sociológica principal") La lógica situacional, 0 el análisis situacional, no sólo no es incompatible con la sociología analítica preconizada por Aguiar, de Francisco y Noguera, sino que ésta no se entendería como alternativa suya. La concepción davidsoniana de la concepción local de la causalidad -a la que aluden los autores- es una ilustración de ello.

f) Dicen los autores del documento: "Nadie necesita añadir el adjetivo 'analítico' a su tarea: la ciencia es 'analítica' por definición" (p. 443). En tal caso, ¿por qué lo añaden ellos?

La tradición o corriente sociológica principal posee, entre otras, las siguientes características (a) exigencia de claridad y rigor conceptual, (b) capacidad de refutación, (c) producción de hipótesis causales, (c) cumulatividad, (d) interpretación analítica de los datos (d) análisis situacional, o de la lógica de la situación, en el que se tienen en cuenta (1) las intenciones de los hombres, (2) las estructuras sociales, que pueden ser agregados emergentes de voluntades, intereses e intenciones, (3) las creencias y conocimientos de los agentes, que pueden ser de naturaleza "irracional", carismática 0 pasional. (mi Carisma y razón, Alianza, 2003.) (4) la identificación de procesos causales identificables. (5) La suposición de racionalidad en el comportamiento humano, habida cuenta de las creencias y los recursos a disposición de los agentes. Y, finalmente, (6) la vinculación con la ética -la producción de una sociología normativa- y con la confianza en lo que he llamado progreso de la conciencia sociológica de la condición humana. El documento examinado también hace hincapié en esta última e interesante característica. (La condición "republicana" de la ciencia social, cuya raíz histórica en el empuje cognoscitivo de la República de las Letras de la llustración no se les escapará) Me consta que sus autores conocen mi propio énfasis sobre el asunto, así que huelga que la elabore ahora.

¿En qué difiere, pues, la sociología analítica propuesta de este modo de hacer sociología? ¿Cómo difiere la sociología analítica de la sociologia perennis? Pienso que no me corresponde a mí responder a estos interrogantes, sino a los autores del escrito, por el que les felicito.

Como he insinuado más arriba, reconozco la ventaja estratégica de formar hoy un movimiento o escuela bajo el nombre de sociología analítica. Le dará visibilidad, capacidad polémica, así como una cierta pugnacidad que redundará al final en beneficio de la buena ciencia social. Tiene marcha para rato, gracias a representantes del calibre de los signatarios del documento. Por eso lo celebro sin ambages. Cuando se haya extinguido el esfuerzo inicial, empero, habrá, sospecho, un retorno al redil. Un redil del que, en puridad, quienes se dedican a la ciencia sociológica no deberían nunca salirse. 